\title{
Kaunas hydropower system management
}

\author{
J. Simaityte ${ }^{1}$, J. Augutis ${ }^{2}$ \& E. Uspuras ${ }^{2}$ \\ ${ }^{1}$ Vytautas Magnus University, Lithuania \\ ${ }^{2}$ Lithuanian Energy Institute, Lithuania
}

\begin{abstract}
The floods occurring in Europe recently confirm that some natural phenomena are unexpected and very difficult to control. Despite this, the proper subjects of infrastructure and scientific institutes try to find common decisions to minimize flood risk levels as much as possible. Currently the European Commission is reviewing legal documents and in the near future EU countries will have to implement flood management directives.

This paper presents a developed mathematical model of flood control which was applied for Kaunas hydropower system. The model consists of two parts: water level calculation algorithms, which were developed using only operational system data, and a risk based water level control model based on an optimization algorithm and integrated risk parameters. The model helps to accept risk based decisions during the flood period and offers alternatives of discharge and water level control near the dam. As a result the flood control characteristics and extreme scenarios are presented.
\end{abstract}

Keywords: risk based decision making, flood management, optimization model.

\section{Introduction}

Floods in recent years have brought huge economical losses and put a significant number of human lives in big danger. In 2006, the European Commission will review and negotiate six legislation acts and one of them is a flood management directive. On 18/01/2006 the European Commission proposed a directive on the assessment and management of floods [1]. Its aim is to reduce and manage the risks that floods pose to human health, the environment, infrastructure and property. Two trends point to an increased flood risk and to greater economic damage from floods in Europe. Firstly, the scale and frequency of floods are likely to increase in the future as a result of climate change, inappropriate river 
management and construction in flood risk areas. Second, there has been a marked increase in vulnerability due to the number of people and economic assets located in flood risk zones.

This paper analyses the main problems of the flood control in the biggest Lithuanian hydropower system (HS) which consists of Kaunas hydropower plant (KHP) and dam, and Kruonis hydro pump storage power plant (KHPS). Both plants use water from Kaunas reservoir which is on the biggest Lithuanian river Nemunas. Extreme inflow from the river is the main initiative event which can impose failure of the system and must be considered, in order to keep acceptable the level of the risk and to ensure safety of downstream population, industry and nature.

Flood control problems in HS are multi objective and complex which requires an optimal solution between many parameters such as: flood inflow into reservoir, nominal water level near the Kaunas dam, nominal water level near the KHPS, discharge thorough the dam, acceptable risk level related with dam failure, acceptable water fluctuation in the reservoir and - also from economical point of view - useful reservoir capacity. The present work is concentrated on the situations related to extreme floods which are bigger than the millennium flood. Statistical analysis of historical river Nemunas floods revealed that floods with a peak of about $3000 \mathrm{~m}^{3} / \mathrm{s}$ can occur once per thousand years. Such kinds of floods are highly dangerous for the Kaunas dam as the biggest discharge thorough the dam is $3990 \mathrm{~m}^{3} / \mathrm{s}$ if all spillways and turbines operate properly. Although there is always the probability that the necessary actions will not be performed or it will be too late to ensure the necessary discharge thorough the dam. One of the purposes of the work is to analyse which scenarios of the flood control near the dam are most dangerous and how to manage the risk level so the economical losses and environmental harm would be as low as possible. The measure of the risk, solving this problem, was assumed as dam overtopping probability, which is the cause of about $50 \%$ of dam failures in the world [2].

The main goals of this work are: 1) water level (WL) control model development; 2) risk parameters integration into WL control model; 3) issues of alternatives of risk based strategies for WL control during extreme flood periods.

\section{WL control model development}

Decisions concerning large structures such as dams are based on different types of criteria, which range from strictly objective to highly subjective. Usually decision making issues used for risk assessment analyses are as follows [2]: a) regulatory type decision process based on standards and criteria; b) normative decision making with explicit or implicit decision rules; c) decision making based on multiple objectives (eg. multiobjective optimization).

The present water level control model was developed under the basis of an optimization algorithm model, as the main task is to create strategies which would find optimal solutions related to the water level near the dam during flood periods. The main input into the model is stochastic - river inflow into the reservoir during flood periods. The next step is real time flood forecasts based on 
online data and historical information. The flood forecast results are integrated into the WL control model which uses the results of a discharge model, risk analysis, a decision making model and also evaluates the extra input. In this case input is extra flow from Kruonis HSP, which also depends on Ignalina operation in abnormal conditions and can be assumed to be stochastic.

The general scheme of the WL control model is presented in Fig. 1. The application of this scheme is explained in section 3 .

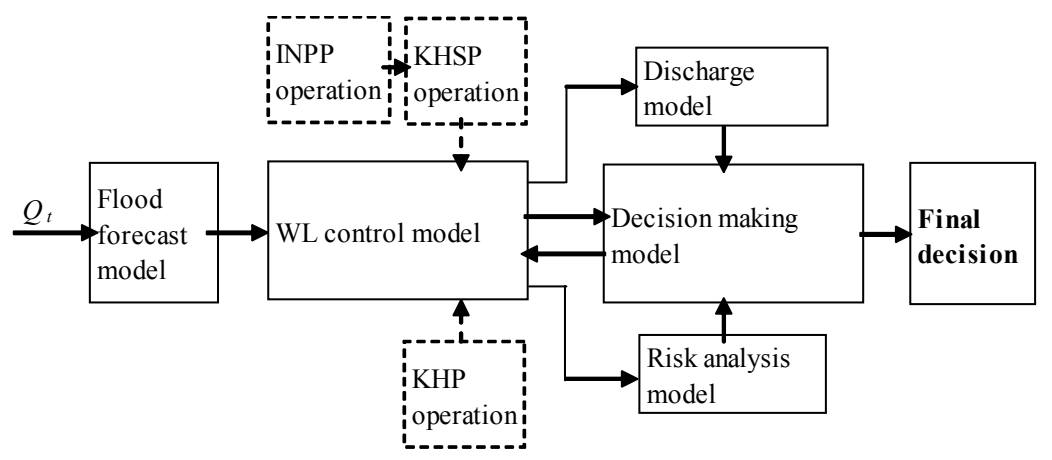

Figure 1: Water level control model general scheme.

\subsection{Water level optimization}

The formulation of any water recourses optimization problem should incorporate all elements that are significantly relevant to system effectiveness [3]. The framework upon which effectiveness is evaluated consists of three components: declaration of decision or independent variables, and state or dependent variables, at time $t$, a discrete time or continuous objective function, or performance criterion $Z$, to be minimized; and a series of constraints that provide for feasible management strategies. In general terms, a discrete time engineering management problem might be formulated.

Let us construct the optimization model for the water level near the dam problem. As the main task of the problem is to find the best strategies for water level control, than the main equation should refer to it:

$$
Y_{t}=F\left(Q_{t}, Q_{t}^{K}, D_{t}^{T r}, D_{t}^{G}, t\right),
$$

where $Y_{t}$ - water level near the dam at time $t ; Q_{t}$ - inflow to the reservoir from the river at time $t ; Q_{t}^{K}-$ inflow to the reservoir from other sources (artificial reservoir) at time $t ; D_{t}^{T r}-$ discharge from reservoir thorough plant turbines at time $t ; D_{t}^{G}$ - discharge from reservoir thorough gates at time $t$.

The function of $Y_{t}$ at the moment $t$ is interpreted as a deterministic function, which has known parameters. But, in fact, the input parameter $Q_{t}$ and sometimes $Q_{t}^{K}$ are stochastic parameters, therefore the evaluation of function $Y_{t}$ can be not so easy. The problem was solved using a simplified operational model, which let one update function $Y_{t}$ parameters at every time $t$ step using a recursive link and 
operating controllable input variable $D=D_{t}^{T r}+D_{t}^{G}$. The stochastic model input is flow into the reservoir $Q=Q_{t}+Q_{t}^{K}$. The model scheme is presented in Fig. 2.

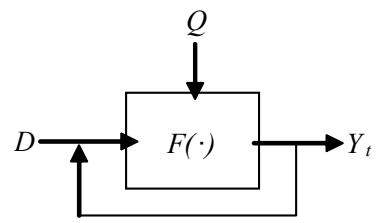

Figure 2: Water level function parameters estimation.

Note $R_{t}$ as a dam overtopping probability dependent on water level near the dam, which indicates hydropower system risk level. Value $R_{t}$ can have various expressions, such as dam overtopping or dam failure probability, number of fatalities during dam failure, economical losses, etc. Water level function $Y_{t}$ is a variable dependent on many contributors, which also are the main elements in the discrete objective function $Z$, so we have the optimization model:

$$
\operatorname{Min} Z=\sum_{t=1}^{T} f\left(R\left(Y_{t}\right), Y_{t}, Q_{t}, Q_{t}^{K}, D_{t}^{T r}, D_{t}^{G}, t\right) .
$$

The constraints of the model in the WL control problem have the following expressions:

$$
\begin{aligned}
& D_{t}^{T}=G_{1}\left(Y_{t-1}, t\right), \\
& D_{t}^{G}=G_{2}\left(Y_{t-1}, t\right), \\
& \underline{Y} \leq Y_{t} \leq \bar{Y} .
\end{aligned}
$$

These constraints show that the discharge also depends on water level, which makes the problem more complicated. $G(\cdot)$ is the functional relationship between the water level and discharge. When $Y_{t-1}$ is given, than $D_{t}^{T r}$ and $D_{t}^{G}$ are obtained by using interpolation methods. The inequality in (6) represents the boundaries of the water level fluctuations, which also can be defined as functions. These boundaries are related with the restrictions for WL fluctuations.

As the function $Z$ in this case is discrete, using numerical calculations we solve (5) and (6) and under the given uncontrollable values $Q_{t}$ and $Q_{t}^{K}$ we find the optimal values of $R\left(Y_{t}\right), Y_{t}, D_{t}^{T r}$ and $D_{t}^{G}$ which are used in the decision making model. If these values agree with risk criteria, than the final decision is formulated for the WL control strategy at a time $t, t+1, \ldots T$, where $T$ is a time interval with sufficient confidence level for $Q_{t}$ forecast.

\subsection{Water level risk based control}

The interaction of the Risk analysis model and Decision making model (Fig.1.) generates alternatives according to the flood situation. After evaluating the water 
level at the dam, it is necessary to evaluate the risk level which the system reaches at a time $t$ (dam overtopping probability) [4]. Than using the flood forecast model the water level $Y_{t}$ is evaluated for a few days onrward, $t=1,2, \ldots$ $n$, where $n$ is the number of days, hours or another time lag. If after $n$ time intervals WL does not reach the critical water level $Y_{c r}$, than the decision alternatives for the next time lags are selected using the deterministic WL model (5), which evaluates the necessary discharge thorough the dam and does not directly integrate additional risk parameters.

The risk based decisions are important, when after a selected time interval the situation is critical, and

$$
Y_{n}-Y_{c r}=r, r>0 .
$$

This means that the water level exceeded the critical dam water level and loads on the dam body are unacceptable. The risk level is calculated considering several scenarios that in the time interval $[1, n]$ it is impossible to manage the situation, and the probability of overtopping is evaluated. If the evaluated probability exceeds the criteria, developed for a specific dam, the extra control actions must be activated: the water level must be lowered in advance by the value $r$, in order to avoid the unacceptable risk level.

It is necessary to mention that the WL control model in this situation not only considers the risk based decision but also at every time step re-evaluates the objective function $Z$ (6). And the last issue of the modelling in this situation is the final decision, which presents the strategies of discharge thorough the dam and keeps an acceptable risk level for the system.

\section{Risk WL control model application}

\subsection{Data analysis and functional relationships}

The developed WL control model (section 2) was applied for Kaunas hydropower system. The primary analysis steps were to find functional relationships between the main hydropower system parameters: $Y_{t}, Q_{t}, Q_{t}^{K}$, $D_{t}^{T r}$ and $D_{t}^{G}$. For this purpose the statistical and operational hydropower system data were used. The dependence of inflow and flood volume can be expressed as

$$
V_{t+1}=\left(Q_{t}+Q_{t}^{K}\right) \cdot \Delta t
$$

where $\Delta t$ is one day time interval between $t$ and $t+1$ with unit in s. Flow measurements $Q_{t}$ and $Q_{t}^{K}$ are in $\mathrm{m}^{3} / \mathrm{s}$ and food volume $V_{t+1}$ is in $\mathrm{m}^{3}$.

The operational data showed the relationship between reservoir volume $V_{t}^{R}$ and WL near the dam. A non-linear dependence at time moment $T$ was obtained:

$$
Y_{t}=\alpha_{1} \log V_{t}^{R}+\beta_{1} .
$$

where the parameters evaluated were $\alpha_{1}=7.24$ and $\beta_{1}=0.08$. 
The other important relations are between the WL, discharge thorough the gates and discharge thorough the turbines. Analysing KHP operational data it was noticed that significant water amount during the flood period used to be discharged thorough the turbines. According to the specifications, the discharge through the turbines depends on the downstream water level and the upstream water level near the dam. A nonlinear dependence of the discharge thorough the turbines and the difference of water levels was determined, when four turbines operate (Fig. 3.):

$$
D_{t}^{T r}=\alpha_{2} H_{t}^{2}+\beta_{2} H_{t}+\gamma_{2}
$$

where $H_{t}=Y_{t}-Y_{t}^{\text {low }}, Y_{t}^{\text {low }}-$ downstream $\mathrm{WL}$ of the dam. The parameters evaluated respectively were $\alpha_{2}=-8.852, \beta_{2}=255.22, \gamma_{2}=-1135.2$.

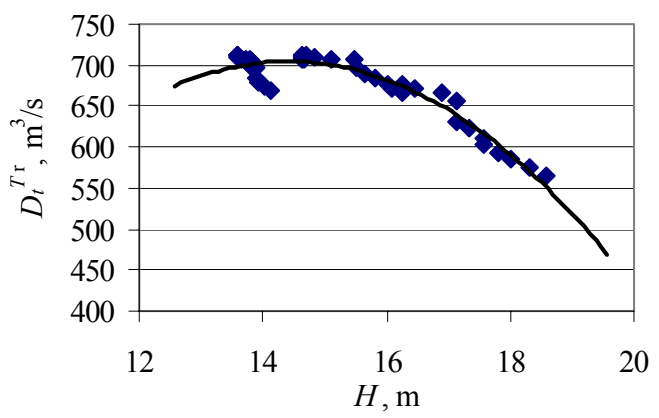

Figure 3: Relationship between turbine discharge s and difference of levels $\mathrm{H}$ to the Kaunas dam.

The functional relations of discharge thorough the gates are linear:

$$
D_{t}^{G}=\alpha_{j} Y_{t}+\beta_{j} \text {. }
$$

The evaluated coefficients of the equation are presented in Table 1. Coefficients $\alpha$ and $\beta$ are dependent on $c$ - how much the gate is opened, in meters.

Table 1: The coefficients of linear dependence between WL and discharge.

\begin{tabular}{|c|c|c|}
\hline $\mathrm{c}$ & $\mathrm{A}$ & $\beta$ \\
\hline $0.41 \mathrm{~m}$ & 1.01 & 37.92 \\
\hline $0.84 \mathrm{~m}$ & 10.49 & 56.06 \\
\hline $1.73 \mathrm{~m}$ & 13.62 & 137.35 \\
\hline $2.21 \mathrm{~m}$ & 15.00 & 209.00 \\
\hline $2.69 \mathrm{~m}$ & 38.37 & -1301.10 \\
\hline $3.18 \mathrm{~m}$ & 23.536 & 326.57 \\
\hline $7.00 \mathrm{~m}$ & 189.39 & -7528.00 \\
\hline
\end{tabular}




\subsection{Kruonis HPS and Ignalina NPP operation}

The Kruonis hydro pump storage power plant was constructed as the main auxiliary power supply system for the peak energy demands. The main function of KHSP is the balancing of electricity generation and consumption as well as the prevention of accidents and their liquidation in the power system. To liquidate the capacity deficit in the event of the disconnection of the Ignalina Nuclear Power Plant (INPP), the Kruonis Pumped Storage Plant generators are automatically launched into operation. KHPS uses other systems energy for water supply from Kaunas reservoir to its artificial reservoir, and when there is a large energy demand it is working on turbine mode and producing electricity. KHSP artificial reservoir volume is 48.78 millions $\mathrm{m}^{3}$, installed capacity of the pumped storage plant $900 \mathrm{MW}$ (4 units, $225 \mathrm{MW}$ each), maximum discharge at turbine mode $226 \mathrm{~m}^{3} / \mathrm{s}$. Usually, when Ignalina NPP operates in normal regime than 1, 2 or sometimes 3 turbines are working in KHSP.

In risk based decision making analysis the important thing, concerning KHSP and INPP, is the plants operation during a flood period. The most critical period would occur if the WL near the dam already reaches maximum limit, and INPP shutdowns, than KHSP would start to work automatically by total capability and would give extra inflow into Kaunas reservoir. This scenario was included into the model and influenced the most critical decisions made during extreme flood periods.

\subsection{Risk analysis model and flood forecast}

The risk analysis model [4] was complemented by additional analysis including more parameters: the water level at the dam at every time step and the inflow of the KHPS, as these can influence the system risk level. The risk level value for the present model step was chosen as discharge unavailability through the dam probability, which was calculated at every time step using a developed event and fault tree model. When the flood begins, the algorithm does extra calculations which indicate the discharge unavailability probability dependent on the current situation, i.e. if 0,1 or 2 gates are already opened and flood forecast results are known, what is the probability that $3,2,1$ or 0 gates will fail to open. Virtually, in this case, the evaluated probability also means the dam overtopping, if no action will be taken to emerge successfully from the critical situation. For example, if one gate is opened and extreme flow is coming into the reservoir, it is possible to evaluate the necessary amount of water which must be discharged thorough the dam in the further time steps. Let us assume, in this situation one gate must be opened during the following two time steps (two days). So if one gate will fail to open, the water level will increase until the critical and dam overtopping will occur. In this example, dam overtopping probability will be equal 2.0E-04. According to the assumed criteria, extra actions must be taken to lower the evaluated risk level; therefore, in order to have some conservatism, it is recommended to increase the discharge as soon as possible in order to have acceptable risk levels in two days. If the risk level is acceptable, no extra actions are necessary at the moment, only those which are foreseen for ordinary flood control. 
Table 2: $\quad$ Probabilities to fail to open the gates at different scenarios.

\begin{tabular}{|c|c|c|c|c|}
\hline $\begin{array}{c}\text { Number of } \\
\text { opened gates }\end{array}$ & \multicolumn{4}{|c|}{ Probability to fail to open the rest or the gates } \\
\hline & No fail & 1 & 2 & 3 \\
\hline 2 & $9.999 \mathrm{E}-01$ & $1.000 \mathrm{E}-04$ & & \\
\hline 1 & $9.998 \mathrm{E}-01$ & $2.000 \mathrm{E}-04$ & $1.000 \mathrm{E}-08$ & \\
\hline 0 & $9.997 \mathrm{E}-01$ & $2.999 \mathrm{E}-04$ & $3.000 \mathrm{E}-08$ & $1.000 \mathrm{E}-12$ \\
\hline
\end{tabular}

The evaluated probabilities to fail to open the necessary number of gates are presented in Table 2. The calculations are performed for different scenarios dependent on the current situation: that already 2,1 or 0 gates are open.

This part of the modelling is necessary only for a very narrow spectrum of situations: for millennial floods, for which the peak probabilities are from 1.0E04 to $1.0 \mathrm{E}-05$. For preliminary analysis these probabilities were chose as risk level criteria. If the flood peak is less than the evaluated millennial flood, then the situations usually are not critical and the dam manages to emerge successfully. If it is bigger, then extra actions will not help to manage the situation.

The results of the risk analysis model are used in a further step - the decision making model, which integrates all available information: actual river flow and its forecast, water level, discharge and also KHSP flow as an unexpected event at a time $t$.

The principle of the forecast is statistical analysis of the historical spring flood, which exceeds the base level. When the individual flood has its first day flow measurements, the model analyses historical floods, and attributes the special weight coefficients for each flood flows and then the future flood flows are calculated. The forecast model parameters are updated every day, using Bayesian techniques, when new flow data are included into the model. To obtain better results the probabilistic model must be integrated with a deterministic hydrological flood forecast model. The details of the flood forecast model can be found in [5].

\subsection{Decision making model}

A risk based decision making model was applied to analyse the most critical situations in Kaunas HS related with extreme floods and all characteristics described in the previous sections, where evaluated using extreme flood data.

Let us analyse the situation of spring floods with maximum peak of $1055 \mathrm{~m}^{3} / \mathrm{s}$ (1999 year flood). The developed water level model, presented in section 2.1, was applied in order to analyse the possible discharge alternatives. For the same situation applying the risk based decision model the results were found to be the same as applying the developed deterministic WL control model without risk parameters, because the risk levels were not exceeded in all time steps. An example of the results is presented in Figure 4.

The situation can be different when the coming flood peak is bigger than $3000 \mathrm{~m}^{3} / \mathrm{s}$. In this case any failure of the actions can bring overtopping or even 
the failure of the dam. For the decision model application the biggest known flood flow data from 1958 was chosen, for which the peak was $3450 \mathrm{~m}^{3} / \mathrm{s}$. Using the developed model the necessary discharge thorough the dam was evaluated every day, performing presented optimization WL algorithms and using a 3 day forecast. At every time step the model proposes the discharge, which must not exceed the acceptable risk level. Fig. 5 presents an example of one of the generated alternatives, which was accepted using the risk based decision model.

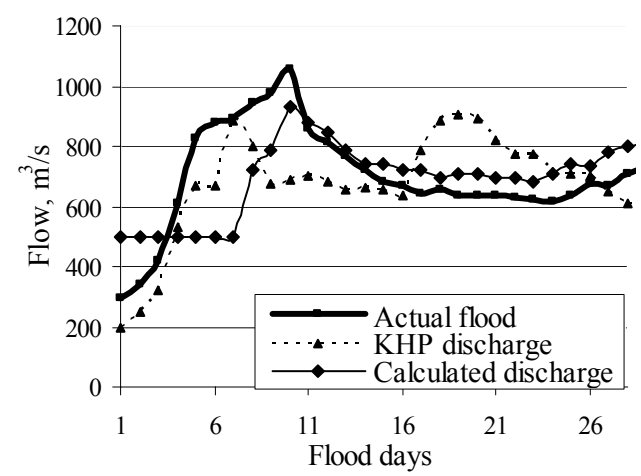

Figure 4: Calculated and operational discharge data for 1999 flood.

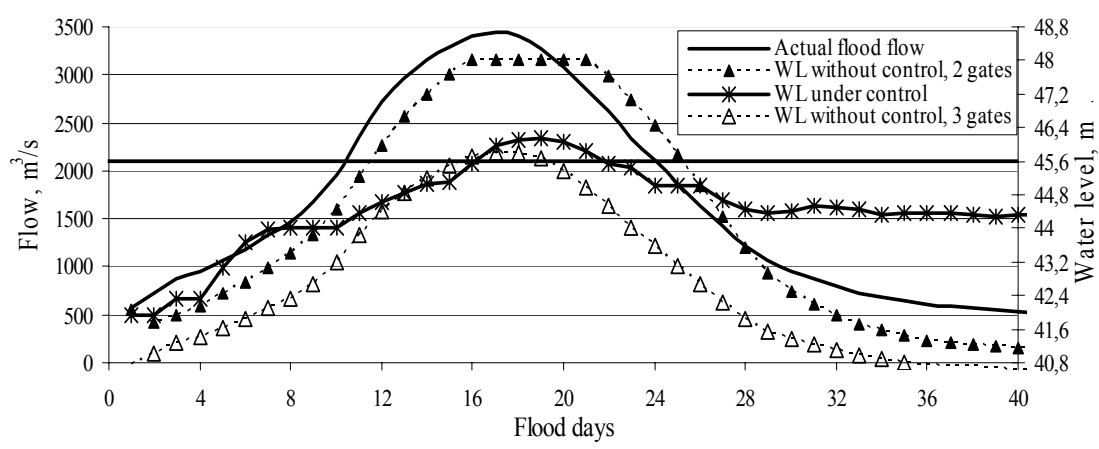

Figure 5: Calculated and operational water level data for 1999 flood.

The solid curve in Fig. 5 shows the flow data of the actual flood. The dashed curve is the water level which would be reached in uncontrollable situation: WL reaches the top of the dam in 14 days when only 2 gates are opened and WL reaches $45.6 \mathrm{~m}$ in 15 days when all 3 gates are opened during all the flood period from the very beginning. The scenario with 3 gates open presents the other extremity: if discharge is very big from the very beginning, dam downstream 
areas can be flooded and economical loses obtained in power generation. So the task is to find a solution in between these two scenarios. The "WL under control" curve shows the water level which it is possible to achieve if the risk based decision model is used: no overtopping of the dam occurs and the critical water level $45.6 \mathrm{~m}$ is exceeded only for 6 days. Also extra conditions were assumed that when the flood passes, the water level near the dam remains nominal $(44 \mathrm{~m})$. This was also achieved using the WL control model.

\section{Results and conclusions}

1. A risk based mathematical model was developed and applied for water level control during extreme flood periods in Kaunas hydropower system.

2. Applying the developed water level control model for floods, for which peaks are less than $3000 \mathrm{~m}^{3} / \mathrm{s}$, the alternatives which were obtained under the risk based decisions are the same as the water level calculated by not applying risk analysis.

3. Risk based decisions for millennial floods decrease dam overtopping probability.

4. Applying the risk based decision model the alternatives of WL control strategies, near the Kaunas dam, are provided.

\section{References}

[1] Proposal for a Directive of the European Parliament and of the Council on the assessment and management of floods, SEC(2006) 66, Brussels, 18.01.2006.

[2] Graham L.P., Bartsch M., Risk analysis safety assessment for use at Swedish dams, Proc. of Symposium on Research \& Development in the field of Dams, Switzerland, 1995.

[3] Nicklow J.W., Discrete-Time Optimal Control for Water Recourses Engineering and Management, Water International, Volume 25, Number 1. P. 89-95, ISSN 0250-8060.

[4] Simaityte Volskiene J., Augutis J., Uspuras E. Kriauciunene J. Risk Analysis of Kaunas Hydropower System // Proceed. of the 4th on Computer Simulation in Risk Analysis and Hazard Mitigation, Rhodes, Greece, 27-29 September 2004. ISBN 1-85312-736-1. - P. 554-561.

[5] Simaityte Volskiene J., Uspuras E., Augutis J. Flood Forecast Model and Probabilistic Analysis // Proceed. of the 7th Intern. Conf. on Probabilistic Safety Assessment and Management, Berlin, Germany 14-18 June 2004. Springer-Verlag. ISBN 1-85233-827-X. - 2004. - P. 3079-3085.

[6] Simaityte Volskiene J. Maximal Floods forecast of the Nemunas River (in Lithuanian) // ISSN 0235 - 7208. Energetika, 2005, Nr.1. P. 34-39. 